\title{
Compliance with National Institute for Health and Clinical Excellence guidelines on weekly re-screening of nutrition risk status is poor
}

\author{
M. Gibbs ${ }^{1}$ and C. E. Weekes ${ }^{2}$ \\ ${ }^{1}$ School of Biomedical \& Health Sciences, King's College London, Stamford Street, London SE1 9NH, UK and Department \\ of Nutrition \& Dietetics, Guy's \& St Thomas' NHS Foundation Trust, Westminster Bridge Road, London SE1 7EH, UK
}

A validated nutrition screening tool (NST) based on four variables, i.e. weight, height, recent unintentional weight loss and poor dietary intake $^{(1)}$, was launched in an Acute Hospital Trust in 2000. In 2006 the Trust Nutrition Steering Committee made NST completion mandatory for all inpatients on admission and weekly throughout hospital stay, to comply with National Institute for Health and Clinical Excellence guidelines $^{(2)}$. A recent audit shows current NST completion rates on admission are approximately $60 \%{ }^{(3)}$. The aim of the present study was to determine the percentage of patients re-screened weekly throughout hospital stay.

The audit was conducted on four wards, three of which had been audited previously. Each ward was audited for 1 week. The end-of-bed charts and medical notes of all patients were reviewed and the number of NST completed (partially or fully) on admission and weekly throughout hospital stay was recorded. $\chi^{2}$ tests were conducted to test for differences between wards.

\begin{tabular}{lccccc}
\hline & $\begin{array}{c}\text { Elderly } \\
\text { care }\end{array}$ & $\begin{array}{c}\text { General } \\
\text { medicine }\end{array}$ & $\begin{array}{c}\text { Acute } \\
\text { admissions }\end{array}$ & Cardiac & $P$ \\
\hline Length of stay (d): Mean & 14 & 11 & 2 & 4 & $<0.01$ \\
Range & $3-81$ & $2-100$ & $1-7$ & $1-44$ & - \\
Patients $(n)$ & 30 & 21 & 77 & 59 & \\
Screened on admission & & & & & \\
$\quad n$ & 25 & 17 & 58 & 13 & $<0.01$ \\
$\%$ & 83 & 81 & 75 & 22 & \\
Re-screened & 10 & 1 & & & \\
$n$ & 33 & 5 & 0 & 1 & 0.223 \\
$\%$ & & & & & \\
\hline
\end{tabular}

Fifty-four (29\%) patients were in hospital for $>7 \mathrm{~d}$ and thus should have been re-screened at least once. Ten (18.5\%) patients were rescreened, the majority $(n)$ being on the elderly care ward. Median number of re-screens was two (range 1-8). A further thirty-three $(61 \%)$ patients showed evidence of re-weighing (an element of the NST) during their hospital stay but no evidence of re-use of the NST.

The current study suggests that while NST completion rates on admission may be good, re-screening rates are poor. Although a majority of patients who were in hospital for $>7 \mathrm{~d}$ were weighed regularly, there was a failure to recognise that recording of other variables, i.e. unintentional weight loss and poor dietary intake, is necessary for correct recognition of nutrition risk status.

1. Weekes CE, Elia M \& Emery PW (2004) Clin Nutr 23, 1104-1112.

2. National Institute for Health and Clinical Excellence (2006) Nutrition Support in Adults: Oral Nutrition Support, Enteral Tube Feeding and Parenteral Nutrition. Clinical Guideline 32. London: NICE.

3. Gibbs \& Weekes (2008) Formal support from senior nursing management results in improved nutrition screening tool completion rates. Proc Nut Soc 68, E40. 